\title{
LECTURA DEL GUIÓN VIAJE A LA LUNA DE FEDERICO GARCÍA LORCA Y DE LA ADAPTACIÓN FÍLMICA DE FREDERIC AMAT
}

Federico García Lorca's Viaje a la luna's Script Reading and Frederic Amat's Film Adaptation

Macarena Roca Leiva*

Resumen

El presente estudio establece las divergencias producidas en la recepción del guión Viaje a la luna (1929) de Federico García Lorca y la adaptación cinematográfica realizada por Frederic Amat (1998). Tanto el guión como la película presentan disparidades en su actualización, debido a las diferencias entre lector y observador, desplazamientos que serán analizados a partir de los conceptos esenciales de la teoría de la lectura de W. Iser y los niveles estructurales de R. Barthes.

Palabras clave: Guión literario, relato, adaptación fílmica, procesos de recepción.

Abstract

The present study seeks to establish the divergences produced in the reception of the script Viaje a la luna (1929) from Federico García Lorca and the cinematographic adaptation carried out by Frederic Amat (1998). Both stories-written and cinematographical-present dissimilarities in their actualization due to the difference between reader and observer. The displacements between both productions will be revised from the essential concepts of Wiser's theory of the reading and R.Barthes's structural sequences.

Key words: Literary script, story, film adaptation, reception processes.

\section{CONFIGURACIÓN DE OBRA LITERARIA: TEXTO Y LECTOR}

La teoría de la recepción postula que en una obra literaria se debe considerar tanto el texto actual como los actos de su recepción. Esta premisa atiende a que la verdadera actualización de una obra literaria será el momento de la concreción dada por la lectura. De esta condición referida por Iser (1989) se desprende que la obra poseerá siempre dos polos: el artístico creado por el autor, y el estético, entendido como la concreción realizada por el lector de acuerdo a los enunciados presentes en el texto. A la luz de estas consideraciones se establece que la dinámica del texto no puede ser reducida a uno de los polos, sino que dependerá de la realidad del texto y de las disposiciones que constituyan al lector al momento de su actualización. Este proceso de interacción está regulado por ciertas estructuras sistémicas que permiten revelar la verdadera capacidad de alcance de una obra escrita. El alcance de esta cooperación encuentra su estructura en los llamados objetos representados y lugares de indeterminación, 
fenómenos promovidos por la actividad lectora que posibilitan la participación, de acuerdo al horizonte enciclopédico del sujeto lector. Ingarden (1989) establece como objetos representados aquellos que el texto narra explícitamente y que se articulan mediante la lectura del texto actual. Éstos, que pueden ser personajes, situaciones, objetos u otras disposiciones descritas por los enunciados, tienen algunas caracterizaciones imprecisas que exigen ser llenadas o completadas por el lector. Los aspectos y detalles que permiten perfilarlos recaen en la tarea constructiva de éste, quien mediante las condiciones dadas por la narración puede concretar el objeto en su mente, dotado de una guiada subjetividad personal.

Este proceso de concreción se enfrenta a momentos en los que la obra literaria no nos entrega la suficiente información mediante sus enunciados para llenar los vacíos que se encuentran. Estos son los llamados lugares de indeterminación "(es decir), cuando no es posible señalar si cierto objeto o situación posee cierto atributo" (Ingarden, 1989:36). Esos lugares indeterminados por los sintagmas del texto, requieren de la actividad memorística e imaginativa del lector, ya que cuanto más avezado en experiencias sea éste, el lugar de indeterminación será no sólo completado sino que, además, adquirirá un mayor valor en cuanto a significado.

Iser, a partir de los conceptos lingüísticos trabajados por Ingarden, construye un estudio fenomenológico sobre la conducta representativa del lector. Señala que la visión imaginaria, a diferencia de la visión óptica o perceptiva, presupone la ausencia material de lo visto. Esta distinción postula dos modos de acceso al mundo: la percepción implica la preexistencia del objeto observado, mientras que la representación consiste, constitutivamente, en su relación con algo no dado o ausente. El paralelismo entre ambos tipos de visión -imaginaria y óptica- permite problematizar las distinciones que se suscitan entre texto literario y adaptación fílmica. Para Iser, hay cierta decepción en las adaptaciones cinematográficas debido a la relativa pobreza de las percepciones. La imagen resultante del proceso de lectura parece ser más rica que la dada por la proyección fílmica y la diferencia estriba en que en la película hay una percepción óptica con preexistencia del objeto; en otros términos, asistimos a la previa concreción de un lector (trabajo de dirección). Los objetos percibidos tienen, en comparación con las imágenes mentales u objetos representados, un grado superior de determinación, lo que no permite niveles de concreción como los elaborados en el proceso de lectura. Es precisamente esa determinación la que se recibe como una decepción o empobrecimiento. Nuestras imágenes mentales no tienden a hacer vivir físicamente personajes del texto literario ante nuestros ojos. Su pobreza óptica se traduce en no hacer aparecer al personaje como objeto sino, más bien, como portador de una significación. En general, no leemos la descripción del personaje en tanto que descripción pura y simple, sino que nos preguntamos por lo que tal representación puede significar. Por consiguiente, la ausencia del objeto 
no constituiría la diferencia esencial entre representación y percepción, sino la validez — en cuanto significación — que el objeto instala en su manifestación

La imagen (de un objeto representado) no cesa de transformarse durante la lectura, el reflejo proyectado de una faceta en otra nos obliga a matizar y reestructurar la representación que vamos imaginando. Este proceso surge cuando el personaje presenta un comportamiento disímil, las facetas se entrechocan y debemos revisar nuestra representación (Ingarden, 1989:156).

Para Iser, de este proceso se concluyen dos diferencias entre texto literario y adaptación fílmica: Primero, mediante la representación producimos una imagen del objeto que, a diferencia de la percibida, no está dada y, segundo, en la película, el agente humano no tiene tarea de producción. La imagen proyectada me excluye del mundo de cuya formación previa no he participado. La versión fílmica de un texto literario neutraliza la actividad de composición propia de la lectura; en otras palabras, no se produce el proceso de lectura o el trabajo de concreción.

Al pensar los modos de recepción del relato, la lectura no se muestra como un acto exclusivo de la literatura. Siguiendo a Barthes, si por relato entendemos todo aquello que puede ser soportado por "el lenguaje articulado, oral o escrito, por la imagen, fija o móvil, por el gesto y por la combinación ordenada de estas sustancias" (1966:65), ${ }^{1}$ la posibilidad efectiva de producir lecturas centradas en el cotejo de los niveles de significación (Gimferrer, 2005) o analogía (Sánchez Noriega, 2002) entre una obra literaria y su adaptación cinematográfica es totalmente posible.

\section{ANTECEDENTES DE VIAJE A LA LUNA DE LORCA PARA LA LECTURA DEL GUIÓN}

La escritura del guión Viaje a la luna se inserta en el nuevo proceso estético que vive García Lorca durante su estadía en Nueva York. Es cuando conoce al pintor y cineasta mexicano Emilio Amero, con quien comienza a trabar una amistad y nuevos impulsos artísticos ${ }^{2}$ de donde, se arguye, surge la escritura del guión cinematográfico.

\footnotetext{
${ }^{1}$ En un relato se encuentran niveles de lectura y de organización que permiten hallar la descripción y el sentido de lo descrito. Es así como en su estructura se imbrican dos planos: el horizontal que entrega, mediante la concatenación de las frases, las informaciones descritas, y el vertical que entrega el sentido último del relato en sí. A partir de esto, encontramos dos tipos de relaciones en todo relato. La primera es la distributiva, la cual se produce si las relaciones entre las unidades de lenguaje están en un mismo nivel, y la segunda es la integrativa, la que se produce si las unidades de lenguaje son captadas de un nivel a otro. $C f r$. Barthes 1977:76-78.

${ }^{2}$ Siguiendo algunas consideraciones de Gubern, podría haber cierta vinculación con el filme experimental 777 recientemente realizado por Amero (1999:449).
} 
Estudiosos de la obra y vida de García Lorca han señalado que Viaje a la luna es una respuesta al filme Un perro andaluz (1929) de Luis Buñuel. Sin embargo, Ian Gibson (1998) en un trabajo biográfico sobre Lorca establece que no fue posible que el poeta viera el filme durante su breve paso por París. Lo más plausible, antes de la redacción de Viaje a la luna, es que haya escuchado comentarios de la película de Buñuel e incluso que haya leído el guión en Nueva York en alguna de las revistas que lo editaron. ${ }^{3}$

Viaje a la luna cuenta con semas recurrentes que permiten articular la existencia de un mundo simbólico en su interior: ranas, peces, serpientes, gusanos, luna, arlequín, rombos, ojos, piernas, manos, cabezas, vómitos, alambres, pasillos, escaleras; elementos que exponen un mundo en ruinas, violento y, por momentos, incluso sádico. Para Gubern, es necesario no olvidar esta simbología

\begin{abstract}
Aunque Lorca escribió Viaje a la luna cuando rebasó su etapa neopopulista para adentrarse en la surrealista, muchos elementos de aquella persistieron todavía, y su guión ha de conectarse con la sensibilidad mostrada en El público y en Poeta en Nueva York, pero sin romper con su humus poético original (1999:451).
\end{abstract}

Aun cuando esta nueva etapa estética sea considerada como la más rupturista en el poeta, su escritura sigue emparentada con el universo mítico presente en toda su producción literaria anterior. Gustavo Correa (1970) en su estudio sobre el universo mítico en la escritura de García Lorca señala que existe un sustrato simbólico que nutre toda la obra, por lo cual sería posible fijar vínculos entre ellas a partir de la presencia - y oposición — de sus símbolos. Correa señala que Poeta en Nueva York "plantea el problema de la doble visión poética de la realidad: una visión plástica y una visión simbólica" (171). A la vez, recalca que este texto responde a la ausencia o muerte del mito, debido a la permanente presencia de símbolos negativos, como "cadenas y ruidos", "aguas podridas", "negras palomas", "inmensas escaleras". ${ }^{4}$ La presencia de estos símbolos, articularían el término del mito en la poesía lorquiana y la "significación de la pérdida del ser" en el hablante (172). De este modo, se nos revela un mundo poético en pugna entre dos tiempos y espacios: infancia y adultez.

El análisis establecido por Correa permite reflexionar sobre semas que también están dispuestos en la escritura del guión de Viaje a la luna. Por ejemplo, en "Poema doble del lago Eden", el poeta nos dice: "Dejarme pasar la puertal

\footnotetext{
${ }^{3}$ La revista surrealista belga Varietes (julio), y las francesas Revue du Cinéma (noviembre) y La Révolution Surréaliste (diciembre). (Cfr. Gubern, 1999:449).

${ }^{4}$ Podemos ver en el poema "La Aurora" - de Poeta en Nueva York - un nuevo locus desde donde enuncia el poeta. Se eliminan las posibilidades de vida natural y humana y se imprime un tono apocalíptico en versos como éstos: "La aurora llega y nadie la recibe en su boca/ porque allí no hay mañana ni esperanza posible" (119).
} 
donde Eva come hormigas y Adán fecunda peces deslumbrados" (123) puerta, hormigas, peces —que hemos marcado con cursiva — son símbolos que también emergen en el guión dándole un carácter poético, lo cual es intensificado en la adaptación de Amat. A su vez, "Paisaje de la multitud que vomita" es un texto que, mediante la imagen metafórica de una mujer obesa, denuncia la gula de consumo que arrasa con la sociedad; una imagen antropomórfica del poder y la corrupción del dinero. En la sección final del poema encontramos versos como los siguientes que enfatizamos con cursivas

Llegaban los rumores de la selva del vómito

con (...) camareros incansables

que sirven platos de sal bajo las arpas de la

saliva.

Sin remedio, hijo mío, jvomita! (103)

Esta representación en la visión imaginaria del lector también es parte de los objetos representados en Viaje a la luna. Lorca desde su corriente de imágenes mentales ha logrado configurar en el poema y en el guión la representación de su universo simbólico. En las secciones (50) y (55) del guión, encontramos

50 (...) varios muchachos vestidos de esmoquin. El camarero les echa vino pero no pueden llevárselo a su boca. Los vasos se hacen pesadísimos y luchan en una angustia de sueño (...) el camarero llena sin cesar los vasos, que ya están llenos (...) / 55.

Aparece una cabeza que vomita. Y en seguida toda la gente del bar que vomita (179-80).

Estas intertextualidades entre Poeta en Nueva York y Viaje a la luna muestran que el guión de Lorca requiere ser leído a partir de las producciones poéticas surgidas en el ciclo neoyorquino. Además, en Poeta en Nueva York la doble visión poética de la realidad - plástica y simbólica $-{ }^{5}$ debe ser entendida como un trabajo proveniente de la asimilación de lo popular y de lo moderno en el poeta. El ciclo del 29 evidencia una comprensión e integración de la vanguardia de una forma perspicaz y tamizada, ajena a la gran mayoría de excesos y experimentaciones de la época.

\section{PERCEPCIÓN DE LA CONCRECIÓN: El RELATO DE FREDERIC AMAT}

Se ha apuntado que el trabajo de adaptación de Amat, ${ }^{6}$ respeta completamente la intención surrealista del texto lorquiano y que posee una secuencia visual bastante

\footnotetext{
${ }^{5}$ Las imágenes surrealistas poseen esa cualidad plástica y simbólica para Correa, ya que no son sólo un simple material visual, sino una correcta proyección de lo onírico.

${ }^{6}$ Frederic, Amat. Dir. Viaje a la luna. (CD), España, 1998. Guión: Federico García Lorca; música: Pascal Comelade; producción: OVIEDO TV, duración: 19’10’.
} 
apegada a las 72 secciones del guión. Sin embargo, el trabajo del pintor se hace notar, sobre todo, en la teatralidad con que fue proyectado y en que las elecciones de la producción dieron como resultado un filme altamente estético y plástico. El cromatismo de los planos, la música escogida para las secuencias y la gestualidad en los cuerpos de los actores, demuestran una puesta en escena perfectamente trabajada desde la comprensión integral de las artes escénicas.

El relato secuencial de Amat nos enfrenta a un trabajo de lectura que, siguiendo a Barthes, no sólo significa

Seguir el desentrañarse de la historia, (sino que) también reconocer estadios, proyectar los encadenamientos horizontales del hilo narrativo sobre un eje implícitamente vertical, (ya que) leer un relato no es sólo pasar de una palabra a otra, es también pasar de un nivel a otro (1977:71).

Si el guión Viaje a la luna presenta dificultades de interpretación debido a que el todo sistémico que nos presenta el texto es de marcada configuración poética, la adaptación - y proceso de lectura — de Amat recoge y amplifica esos núcleos de significación. La lectura del guión lorquiano exige, mediante sus funciones de expansión, una relación integrativa para su correcta y fecunda interpretación.

Otro aspecto a considerar es que García Lorca entrega escasa información en las secciones del guión referentes a la representación de los objetos enunciados (personajes, escenarios, sentimientos). Esta situación no es exclusiva del caso particular estudiado, sino de la ambigüiedad del guión como género. Éste al ser un paso intermedio, es visto sólo como "un proyecto de soporte para el filme" (Gimferrer, 2005:141) y aunque representa un híbrido literario ${ }^{7}$ y un estadio previo a la película, requiere ser analizado desde su condición sui generis en cuanto relato.

La intervención de Amat reside en el actualismo con que, mediante los sistemas cinematográficos contemporáneos, lleva a cabo las imágenes mentales surgidas en el poeta. De todo el proceso destacan algunas secuencias de secciones que reflejan una interacción mayor entre Amat y el guión lorquiano.

Revisemos algunos casos que permiten reflexionar sobre los procesos de lectura y los niveles integrativos en los relatos

Secuencia $(19 / 21)$ :

19. Dos niños avanzan cantando con los ojos cerrados.

20. Cabezas de los niños que cantan llenas de manchas de tinta.

21. Un plano blanco sobre el cual se arrojan gotas de tinta (177).

\footnotetext{
7 "Viaje a la luna es un texto instrumental y transitorio, una matriz literaria preliminar para un proyecto de film, es decir, una larva o embrión textual para su ulterior desarrollo audiovisual, en un sistema semiótico muy distinto" (Gubern, 1999:451).
} 
En la adaptación de Amat corren hacia la cámara dos niños iguales (tal vez gemelos), brincando desnudos y abrazados. La imagen es filmada en blanco y negro y con muy poca definición de los cuerpos. Se escucha una melodía de cuna como música de fondo. Poco a poco, la tonada comienza a desafinar provocando en el espectador una sensación de temor e inseguridad. La secuencia termina con una imagen que emula el término de una cinta o rollo fílmico. Estas secciones anticipan al observador a la irrefutable pérdida de la inocencia.

En esta secuencia nos encontramos con variaciones entre objeto representado y objeto percibido: los niños saltan enlazados entre ellos y no escuchamos sus cantos, ya que la música de fondo está "narrando" la escena. La producción de Amat ha impreso en esta secuencia un tono trágico inminente que no es posible de representar en la lectura del guión mediante la información entregada en los enunciados del texto. Inmediatamente, la secuencia (23/26) refrenda la angustia percibida por el espectador en el cruce de la imagen cándida de los niños y la música distorsionada

23. Sale un hombre con una bata blanca. Por el lado opuesto viene un muchacho desnudo en traje de baño de grandes cuadros blancos y negros.

24. Gran plano del traje de cuadros sobre una doble exposición de un pez.

25. El hombre de la bata le ofrece un traje de arlequín pero el muchacho rehúsa. Entonces el hombre de la bata lo coge por el cuello, el otro grita, pero el hombre de la bata le tapa la boca con el traje de arlequín.

26. Gran plano de manos y traje de arlequín apretando con fuerza (177).

En la sección 23, el guión sólo nos refiere a "cuadros blancos y negros", los que son percibidos en la adaptación fílmica como una imagen del tablero de dama en el diseño del traje de baño del niño. El lugar indeterminado que Lorca deja en aquella información representa una retención que, propiciada por la lectura de la sección 3 que describe "Pies grandes corren rápidamente con exagerados calcetines de rombos blancos y negros" (176), se integra al objeto representado del traje de arlequín, el cual por definición posee losanges de distintos colores. De ello, se permite pensar que, aunque las indicaciones en el guión sean escasas, hay informaciones subrepticias que se activan mediante una lectura integrativa del texto literario. Pero Amat realiza una insistencia en la lectura de la secuencia. En la sección 24, la cámara se acerca a la entrepierna del niño, lugar en donde se sitúa el pez para la "doble exposición”. El pez, símbolo fálico, es exacerbado en la imagen óptica con su movimiento ondulante, el cual intensifica la percepción de lo lúbrico. Así también, la sección 25 ofrece en la adaptación al espectador la percepción subjetiva de pederastia, la cual en la sección 26 es extremada a sodomía, ya que el niño es flectado sobre una mesa por el adulto en bata. 
Hasta la sección 29 — antes de la aparición del letrero Viaje a la luna — se ha hablado de una introducción al cuerpo de la obra; similar, por lo demás, a lo acontecido en Un perro andaluz. Sin desmedro de ello, estas 29 secciones se perciben en la adaptación de Amat como una breve biografía infantil: juegos pueriles, llanto de niño, peces, pies y piernas como símbolos de miembros viriles y objetos punzantes (Gubern, 1999:450 y ss) tratados con musicalización y técnicas audiovisuales que promueven el pensamiento del receptor hacia esa dirección. Luego, en la secuencia (39/42) Lorca nos entrega un acercamiento de cámara a la mujer española tradicional, la arquetípica, como la matriarca en $\mathrm{La}$ casa de Bernarda Alba (1936)

39. Una mujer enlutada se cae por la escalera.

40. Gran plano de ella.

41. Otra vista de ella muy realista. Lleva pañuelo en la cabeza a la manera española. Exposición de las narices echando sangre.

42. Cabeza boca abajo de ella con doble exposición sobre un dibujo de venas y granos gordos de sal para el relieve (179).

Nuevamente, hay un cambio entre objeto representado y objeto percibido. En este caso no responde a la ocupación de los espacios vacíos del guión, sino a un giro premeditado en la elección del director. La española enlutada en la adaptación lleva su cabello rizado y suelto, por eso, es más cercana al personaje de Adela, mujer que se rebela ante la autoridad de la madre en función de su ser pasional. Esta relectura o reivindicación promovida por Amat es sinécdoque del proceso de lectura que éste hace de la obra y vida del poeta.

La secuencia (45/47) nos entrega imágenes muy emparentadas con el poema de la sección 29: animalitos inválidos o muertos y, sobre todo, la luna que cambia su significado ${ }^{8}$

45. Ya en la calle nocturna hay tres tipos con gabanes que dan muestras de frío. Llevan los cuellos subidos. Uno mira la luna hacia arriba, levantando la cabeza y aparece la luna en la pantalla, otro mira la luna y aparece una cabeza de pájaro en gran plano a la cual se estruja el cuello hasta que muera ante el objetivo, el tercero mira la luna y aparece en la pantalla una luna dibujada sobre fondo blanco que se disuelve sobre un sexo y el sexo en la boca que grita.

46. Huyen los tres por la calle.

47. Aparece en la calle el hombre de las venas y queda en cruz. Avanza en saltos de pantalla (179).

\footnotetext{
${ }^{8}$ En "Luna y panorama de los insectos (poema de amor)", Lorca resemantiza el vocablo luna. Ésta ha dejado de ser la celadora de la noche, la imagen de fecundidad cósmica ante los elementos naturales: "Son mentira los aires. Sólo existe/una cunita en el desván/que recuerda todas las cosas. Y la luna. Pero no la luna" (158).
} 
En la sección 45, el sexo sobre el cual se disuelve la luna y aparece la boca gritando es una vulva. Esta elección de Amat entronca con otras determinaciones escogidas en la adaptación que están en el orden del tono biográfico-sexual de la historia, como también con la lectura integrativa que realiza.

Luego, en la secuencia 46, los tres hombres huyen por la calle, pero la vía no es más que el cuerpo del hombre con venas. Todos corren a lo largo de su cuerpo y en dirección a su sexo. La secuencia finaliza con la llegada de los hombres a la zona del vello púbico, incorporación que hace perceptible la retribución que Amat inscribe en la adaptación. Revisemos la secuencia (65/67)

65. Vuelven a salir las palabras Elena, elena, elena, elena.

66. Estas palabras se disuelven sobre grifos que echan agua de manera violenta.

67. Y estos grifos sobre el hombre de las venas muerto sobre periódicos abandonados y arenques (180-1).

La sección 67 finaliza en la adaptación con una visión óptica de los objetos representados en el guión. Se muestra una larga calle con "periódicos abandonados y arenques", para terminar, la cámara, enfocando un larga y alta chimenea. Estos dos elementos (larga calle y alta chimenea) se insertan en los registros ya encontrados en el trabajo de Lorca: peces, piernas, pies. Dos nuevos símbolos fálicos que, icónicamente, Amat escoge e incorpora a la puesta en escena para incrementar la lectura sexual que ha realizado de Viaje a la luna. La secuencia (68/69) revela —álgidamente - la compensación histórica que la adaptación proyecta sobre la humillación vivida por Lorca

68. Aparece una cama y unas manos que cubren un muerto.

69. Viene un muchacho con una bata blanca y guantes de goma y una muchacha vestida de negro. Pintan un bigote con tinta a una cabeza terrible de muerto. Y se besan con grandes risas (181).

Los lugares de indeterminación presentes en los objetos representados "muchacho con una bata blanca y guantes de goma" y "muchacha vestida de negro", en la visión óptica de la adaptación concluyen en la presencia de un médico y de una viuda. Luego, los enunciados que informan del dibujo sobre el rostro del muerto son completados en escena mediante la elección de unos bigotes dalinianos sobre la mortaja. El lugar de indeterminación es cubierto con un dibujo extratextual con la imagen de Salvador Dalí; sin embargo, no es con la sola imagen con que se genera el diálogo, sino que esta reminiscencia nos lleva a establecer puentes con la relación entre Dalí y Lorca desde sus años en la Residencia de Estudiantes de Madrid. La amistad que Lorca creó con el pintor catalán desembocó en un amor no correspondido y en el posterior distanciamiento 
entre ambos, sin olvidar que existen registros artísticos que establecen una dinámica de creación entre ellos. ${ }^{9}$

\section{SOBRE LA CONFRONTACIÓN DE VIAJE A LA LUNA Y EL SIGNIFICADO DEL PROCESO DE LECTURA}

Viaje a la luna representa el cambio de una sensibilidad y de una estética en García Lorca. Como señala Gustavo Correa (1970), asistimos a la muerte del universo mítico de Lorca en la producción correspondiente a su viaje a Nueva York. Lo más interesante de este texto híbrido — como todo guión- es su carácter experimental, en donde se permite apreciar un trabajo poético icónico; el cruce o desplazamientos de disciplinas que, a partir de la vanguardia, comenzaron a entreverarse, como por ejemplo, palabra e imagen. ${ }^{10}$

Por otra parte, el vocabulario fílmico que Lorca muestra en la redacción de éste ("pasillo recorrido por la máquina", "gran plano de", "doble exposición sobre un dibujo de venas y granos gordos de sal para el relieve") y la visualización cinematográfica de las escenas ("la cámara baja con gran ritmo acelerado", "luna dibujada en la pantalla sobre fondo blanco"), nos permite concluir que la concepción del arte de avanzada o de ruptura no estaba presente sólo en su producción poética, sino que también en la manera de intelectualizar, a través del arte, el universo de la novedad y de la conjunción de disciplinas propuesto por la vanguardia histórica.

Sobre el trabajo realizado por Amat podemos indicar que es una adaptación fiel a las secuencias y descripciones del guión de Lorca siendo, además, una adaptación correcta o adecuada. Esto significa, en términos de análisis adaptativo, que el extremo apego al texto original — la entendida fidelidad — no conduce en

\footnotetext{
${ }^{9}$ En la Residencia de Estudiantes de Madrid, tanto Lorca como Dalí desarrollaban un macabro juego: uno actuaba su muerte y el resto de los amigos asistía a su velatorio. Esta costumbre se inicia en 1918 junto a los poetas "rinconcillistas", con quienes Lorca rodó, fotográficamente, el filme La historia del tesoro en el que actuó la muerte del personaje principal. También hay antecedentes de estas representaciones mortuorias en el viaje de Semana Santa a Figueres y Cadaqués (1925), donde Dalí pintaba a Lorca como cadáver, mientras su hermana Ana María, lo fotografiaba (Gubern, 1999:227-8). A esto hay que agregar "Oda a Salvador Dalî" (1926), El casamiento de Buster Keaton (Da1í, 1925) y El paseo de Buster Keaton (Lorca, 1928), obras que abren interesantes miradas a la comprensión de la sexualidad de sendos artistas. Es tan proteica la conexión intelectual y los mensajes cifrados que ambos se remiten en esos años que Gubern ha señalado, como condición para la comprensión de la gestación de Viaje a la luna, el conocimiento y lectura de todos los antecedentes recién señalados.

${ }^{10}$ En la sección 38 del guión lorquiano, se dice: "Doble exposición de barrotes que pasan sobre un dibujo Muerte de Santa Rodegunda" (178). Esta alusión directa a su propio trabajo de dibujo se hace parte de la noción planteada sobre la comprensión de las artes vanguardistas en el poeta. Gregorio Prieto, en el estudio recopilatorio de los dibujos de Lorca, se refiere a que: "Federico componía sus dibujos como algo que lo divertía. Era como rellenar los huecos del cajón atestado de su poesía" (1949:25). La cursiva es nuestra.
} 
este caso a un producto mecánico y frío desprovisto de la subjetividad del lectordirector. ${ }^{11}$ Es un trabajo fiel, pero, por sobre todo, una adaptación correcta, ya que el nivel de significación logrado es análogo en ambas formas; es decir, el polo estético o receptor recibe mediante esta lectura (del guión y de la película) un mensaje análogo. ${ }^{12}$

Del análisis establecido, se identifican tres aspectos esenciales en la adaptación de Amat. En primer lugar, cuenta con la incorporación de conocimiento paradiegético. Se anexa, a partir de pequeñas modificaciones de las secuencias, referencias a la obra y a la imagen cultural del poeta granadino, lo cual nos sitúa ante una adaptación que ha integrado y personificado lo "lorquiano" como símbolo temático de la película. Por ello, la lectura integrativa en la secuencia del relato, nos arroja —en la adaptación de Amat- un conocimiento que excede los límites del guión. En segundo lugar, la adaptación está icónicamente cargada de sentidos otorgados por Amat a partir, en la mayoría de los casos, de los lugares de indeterminación presentes en el guión. Es decir, Amat finaliza - $\mathrm{u}$ ocupa - los espacios vacíos que se presentan en Viaje a la luna (tarea que es propia de toda adaptación) sumándoles, mediante técnicas del lenguaje cinematográfico, emociones y sensaciones que no se desprenden fácilmente de la lectura del guión. La emoción sugerida en el relato cobra mayor intensidad en los momentos cuando la violencia es ópticamente percibida. Por ejemplo, vómito de los hombres en el bar, manos que estrujan hasta la muerte al pez, a la rana y al pájaro, azote de la madre al niño, agresión del hombre de la bata. La focalización de la cámara, las elecciones de sonidos y melodías, las estrategias de montaje en la edición, la distorsión de las imágenes, la utilización de color y blanco y negro, dan como resultado una nueva forma de satisfacer aquellos espacios indeterminados, en la lectura del texto literario original.

\footnotetext{
${ }^{11}$ Pere Gimferrer establece que no es posible cotejar un texto literario con su adaptación fílmica, ya que al poseer lenguajes distintos (escritural-visual), la comparación entre ellos se vuelve ineficaz. Si dos producciones intelectuales corresponden a géneros distintos, lo único comparable entre ellas es el nivel de significación logrado. "Los problemas de adaptación pueden ser fundamentalmente de dos orígenes: problemas de equivalencia de lenguaje y problemas de equivalencia del resultado estético obtenido mediante el lenguaje" (2005:55).

${ }_{12}$ Podemos indicar que el concepto "mala adaptación" nunca surge del nivel de fidelidad o infidelidad al texto original, sino de la "escasa entidad artística de las películas o por la desproporción existente entre el nivel estético del original y el de la adaptación" (Sánchez Noriega, 2002: 56), aspectos que están muy superados en la lectura adaptativa de Amat. Ante esto, el teórico establece que "[si] el efecto análogo suele vincularse a la fidelidad, al espíritu de la narración literaria; (...) con ello se indican dos hechos íntimamente ligados: el resultado estético equivalente y la capacidad del autor de cine para realizar, con su versión fílmica, la misma lectura que han hecho la mayoría de los lectores del texto literario. Es decir, una adaptación no defraudará si, al margen de suprimir y/o transponer acciones y personajes, logra sintonizar con la interpretación estándar de los lectores de la obra de referencia” (2002:56).
} 
Tercero; Amat responde, mediante su adaptación, a la ofensa dirigida a Lorca en Un perro andaluz. ${ }^{13}$ Esta hipótesis surgida de la revisión de la película se refuerza ante los dichos del mismo director a la prensa en 1998, quien consideraba que "el guión neoyorquino es, a muchos niveles, una cumplida respuesta al agravio" (Gubern, 1999:450). Sin embargo, la adaptación de Amat imprime mayor fuerza a esta contra-ofensa del guión, potenciada con objetos percibidos que surgen de su propia "corriente de imágenes".

$$
\begin{array}{r}
\text { Universidad Adolfo Ibáñez* } \\
\text { Departamento de Literatura } \\
\text { Balmaceda 1625, Recreo, Viña del Mar (Chile) } \\
\text { mroca@ uai.cl }
\end{array}
$$

\section{BIBLIOGRAFÍA}

Barthes, Roland (1966). "Introducción al análisis estructural de los relatos", en Comp. Silvia Niccolini. El análisis estructural. Buenos Aires: Centro Editor de América Latina, 1977:65-101.

Correa, Gustavo. La poesía mítica de Federico García Lorca. Madrid: Gredos, 1970.

García Lorca, Federico. "Viaje a la luna (Guión Cinematográfico)", en Revista de Occidente 211. 1998:176-81.

------ Poeta en Nueva York. Barcelona: Losada, 1998.

Gibson. Ian. Vida, pasión y muerte de Federico García Lorca. Barcelona: Plaza y Janés, 1998.

Gimferrer, Pere. Literatura y cine. Barcelona: Seix Barral, 2005.

Gubern, Roman. Proyector de luna. La generación del 27 y el cine. Barcelona: Anagrama, 1999.

Ingarden, Roman. "Concreción y reconstrucción”, en Estética de la recepción. Ed. Rainer Warning. Madrid: Visor, 1989:35-53.

Iser, Wolfgang. El acto de leer. Teoría del efecto estético. Madrid: Taurus, 1987.

----- "El proceso de lectura", en Estética de la recepción. (Ed.) Rainer Warning. Madrid: Visor, 1989:149-64.

Prieto, Gregorio. Dibujos de García Lorca. Madrid: Afrodisio Aguado, 1949.

Sánchez Noriega, José Luis. De la literatura al cine. Teoría y análisis de la adaptación. Barcelona: Paidós, 2002.

\footnotetext{
${ }^{13}$ Luis Buñuel, dir. Un perro andaluz. (DVD). España, 1929. Guión: Luis Buñuel y Salvador Dalí, duración: 17'. Buñuel señaló que su película no poseía alusiones a la vida de García Lorca. Sin embargo, muchos exégetas no lo creyeron, así como tampoco el poeta.
} 